Revista de la red interuniversitaria de estudios sobre las literaturas rioplatenses contemporáneas en Francia

23 | 2021

La vereda de enfrente. Cruces entre las literaturas argentina y chilena del siglo XX

\title{
Encuesta binacional
}

Responden: Claudia Apablaza, Felipe Becerra, Matías Celedón, Sergio Chejfec, Alejandra Costamagna, María Sonia Cristoff, Diamela Eltit, Yanko González, Betina Keizman, Martín Kohan, Lina Meruane, Cynthia Rimsky y Hernán Ronsino

\section{(2) OpenEdition} Journals

Edición electrónica

URL: https://journals.openedition.org/lirico/11749

DOI: $10.4000 /$ lirico. 11749

ISSN: 2262-8339

Editor

Réseau interuniversitaire d'étude des littératures contemporaines du Río de la Plata

Referencia electrónica

Responden: Claudia Apablaza, Felipe Becerra, Matías Celedón, Sergio Chejfec, Alejandra Costamagna, María Sonia Cristoff, Diamela Eltit, Yanko González, Betina Keizman, Martín Kohan, Lina Meruane, Cynthia Rimsky y Hernán Ronsino, «Encuesta binacional», Cuadernos LIRICO [En línea], 23 | 2021, Publicado el 16 diciembre 2021, consultado el 07 enero 2022. URL: http://journals.openedition.org/ lirico/11749 ; DOI: https://doi.org/10.4000/lirico.11749

Este documento fue generado automáticamente el 7 enero 2022.

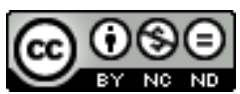

Cuadernos LIRICO está distribuido bajo una Licencia Creative Commons Atribución-NoComercialSinDerivar 4.0 Internacional. 


\title{
Encuesta binacional
}

\author{
Responden: Claudia Apablaza, Felipe Becerra, Matías Celedón, Sergio \\ Chejfec, Alejandra Costamagna, María Sonia Cristoff, Diamela Eltit, Yanko \\ González, Betina Keizman, Martín Kohan, Lina Meruane, Cynthia Rimsky y \\ Hernán Ronsino
}

\section{Claudia Apablaza}

Rancagua, 1978. Ha publicado, entre otros, Diario de las especies (2008), EME / A. La tristeza de la no historia (2010), Diario de quedar embarazada (2017).

1. ¿Qué libro ha releído de la literatura argentina? ¿Por qué motivo(s)?

Cómo me hice monja de César Aira para participar en una actividad dedicada a su obra; Distancia de rescate de Samantha Schweblin por un ramo de crítica del doctorado y también porque la paso en mis talleres.

2. Si tuviera que elegir algún episodio para decir algo sobre las relaciones entre las literaturas argentina y chilena, ¿cuál elegiría y por qué?

Hay algo que me llama mucho la atención, es que en Chile se publican, sobre todo en editoriales independientes, a muchas escritoras argentinas, como Samanta Schweblin, Mariana Enríquez, Marina Mariasch, Selva Almada, Gabriela Cabezón Cámara, Lucila Grossman, Valeria Tentoni, Pola Olaixarac, Ariana Harwicz, entre otras; y en Argentina se publica escasamente a alguna autora chilena.

3. ¿A qué autor/a de la literatura argentina envidia?

A César Aira, porque tiene mucho tiempo para escribir.

4. ¿Qué característica(s) de la literatura argentina pondría de relieve en contraste con la literatura chilena?

Que escriben más bien ficción pura y no tanta autoficción como en Chile. Eso tiene que ver con la tradición.

5. ¿Cuál es el/la autor/a argentino/a más chileno/a?

No sé, no se me ocurre ninguno, pero sí se me ocurre que tal vez el chileno más argentino es Matías Celedón por los riesgos que toma en su escritura.

6. ¿Cuál fue el último libro que leyó de literatura argentina?

¿Por qué volvías cada verano? de Belén López Peiró. 
7. ¿Cuáles son los tres autores argentinos que más ha leído?

César Aira, Borges y Samanta Schweblin.

8. Sigmund Freud dice que para amar hacen falta tres, ¿qué otra literatura podría venir a completar esta escena?

Macedonio Fernández, Gabriela Cabezón Cámara y Ricardo Piglia.

9. ¿Cómo definiría la chilenidad en materia literaria?

Autorreferencial y poética.

\section{Felipe Becerra}

Valdivia, 1985. Ha publicado Bagual (2008) y La próxima novela (2019).

1. ¿Qué libro ha releído de la literatura argentina? ¿Por qué motivo(s)?

Ficciones. También he vuelto a El fiord más de una vez.

2. Si tuviera que elegir algún episodio para decir algo sobre las relaciones entre las literaturas argentina y chilena, ¿cuál elegiría y por qué?

Buenos Aires, años 30. María Luisa Bombal y Jorge Luis Borges -Georgie- van al cine. Película romántica, o de aventuras. Borges y Bombal cuchichean ante la pantalla. Esa noche, mientras pasean junto al río, se cuentan uno al otro lo que escriben por esos días. Al escuchar el argumento de La amortajada, Borges lo reprueba: su ejecución es imposible. Años después reconocería su error. En el episodio hay un cierto desdén, por parte de Borges, que se transforma en extrañeza y luego en una moderada (siempre moderada) admiración. Pero sobre todo me quedo con esa extrañeza, ese no saber qué hacer en Argentina con algunos libros de la narrativa chilena.

3. ¿A qué autor/a de la literatura argentina envidia?

Al leer los diarios de Piglia (o de Renzi), sentí algo de envidia por todo el mercado cultural que permitía a un joven escritor en los años 60 y 70 en Buenos Aires ganarse la vida, aun fuese de manera precaria, a partir de traducciones, trabajos editoriales, adelantos por obras inconclusas, artículos para revistas y periódicos, además de charlas o cursos en universidades, museos o para asociaciones privadas. Pero en realidad al que envidio amorosamente es a Marechal por haber escrito Adán Buenosayres.

4. ¿Qué característica(s) de la literatura argentina pondría de relieve en contraste con la literatura chilena?

Veo al menos dos características de la narrativa argentina que en la chilena escasean: la determinación con la que muchos de sus autores/as elaboran su propia tradición; la mayor frecuencia de la construcción de una obra de manera consciente y sostenida. Quizás en Chile ambos aspectos estén más presentes en su poesía.

5. ¿Cuál es el/la autor/a argentino/a más chileno/a?

El narrador chileno más chileno era argentino: Manuel Rojas. Pero el narrador argentino más chileno nació en Uruguay: Elías Castelnuovo.

6. ¿Cuál fue el último libro que leyó de literatura argentina?

Personas en la sala, de Norah Lange.

7. ¿Cuáles son los tres autores argentinos que más ha leído?

Borges, Macedonio Fernández, O. Lamborghini.

8. Sigmund Freud dice que para amar hacen falta tres, ¿qué otra literatura podría venir a completar esta escena?

La uruguaya. O la literatura de zonas transfronterizas, como la andina en el norte o la patagónica en el sur.

9. ¿Cómo definiría la chilenidad en materia literaria? 
Ercilla entrando en la cueva de Fitón.

\section{Matías Celedón}

Santiago, 1980. Ha publicado Trama y urdimbre (2007), La filial (2012), Buscanidos (2014), El clan Braniff (2018).

1. ¿Qué libro ha releído de la literatura argentina? ¿Por qué motivo(s)?

Literatura de Izquierda, de Damián Tabarovsky. Por militancia.

2. Si tuviera que elegir algún episodio para decir algo sobre las relaciones entre las literaturas argentina y chilena, ¿cuál elegiría y por qué?

Nunca olvidé la franqueza con que un embajador argentino le respondió a un periodista chileno ante una nota mala leche que le hicieron en el diario La Nación de acá. "Con referencia a su libelo del domingo 4 de enero, tengo el agrado de dirigirme a usted en mi carácter de diplomático de carrera y embajador para manifestarle que me chupe un huevo", dijo. En su momento se armó un escándalo y fue destituido, pero tiempo después, en esa misma línea irreverente, Bielsa -el entrenador, no el embajadorrecalcó el valor y la dignidad de la libertad individual por sobre la hipocresía de las formas y el protocolo de lo esperable, dejando con la mano extendida al presidente Piñera cuando oportunistamente quiso saludarlo. Juntos, pero no revueltos.

3. ¿A qué autor/a de la literatura argentina envidia?

A Edgardo Cozarinsky.

4. ¿Qué característica(s) de la literatura argentina pondría de relieve en contraste con la literatura chilena?

Más allá de rasgos puntuales como la ironía y el sentido del humor, que hablan de una literatura extrovertida, con calle y barrio, a diferencia de nuestra propensión a la cavilación intimista, introspectiva, más puertas adentro, creo que en la literatura argentina se da una relación distinta y sin complejos con su propia tradición, en donde la vanguardia siempre ha sido un norte más llamativo que el canon.

5. ¿Cuál es el/la autor/a argentino/a más chileno/a?

En sentido estricto, Hernán Ronsino.

6. ¿Cuál fue el último libro que leyó de literatura argentina?

Eisejuaz, de Sara Gallardo.

7. ¿Cuáles son los tres autores argentinos que más ha leído?

Borges, Copi y Cortázar, probablemente.

8. Sigmund Freud dice que para amar hacen falta tres, ¿qué otra literatura podría venir a completar esta escena?

La de los extranjeros que se mimetizaron en esta zona: pienso en Hudson, Gombrowicz o Caillois, pero también en Rubén Darío.

9. ¿Cómo definiría la chilenidad en materia literaria?

Un personaje en busca de autor.

\section{Sergio Chejfec}

Buenos Aires, 1956. Ha publicado, entre otros, Lenta biografía (1990), Boca de lobo (1999), Los incompletos (2004), Últimas noticias de la escritura (2015).

1. ¿Qué libro ha releído de la literatura chilena? ¿Por qué motivo(s)?

Tanto por relectura como por tenerlo muchas veces presente, El día más blanco, de Raúl

Zurita. A veces se dice que las novelas acompañan, pero creo que más acompañan las 
autobiografías. Cuando se trata de libros que admiramos, la noción de "motivo" parece superflua. Sin embargo vale la pena explicar. Creo que la autobiografía de Zurita me fascina porque es un relato cultural escrito en tono muy bajo, como si la opción del poeta casi místico fuera asomarse a su vida en clave casi verista, con una mirada de infancia neorrealista.

2. Si tuviera que elegir algún episodio para decir algo sobre las relaciones entre las literaturas argentina y chilena, ¿cuál elegiría y por qué?

Se me ocurre un episodio privado. Estábamos hace muchos años en la casa de Diamela Eltit en Buenos Aires, alrededor de cuatro o cinco escritorxs argentinxs. Ella es una gran anfitriona, entre otras cosas grandes que es. En un momento de la reunión un teléfono comenzó a sonar. No era el de la casa. Sonó por largo rato, nadie se dio por aludido hasta que cesó.

3. ¿A qué autor/a de la literatura chilena envidia?

Envidio las libretas de Ariel Richards, las postales de Felipe Cussen y la librería de Sergio Parra. Supongo que podría envidiar su apartamento, pero no lo conozco.

4. ¿Qué característica(s) de la literatura chilena pondría de relieve en contraste con la literatura argentina?

Creo que la literatura chilena es más vertical que la argentina. Un poco como el mapa. Los escritores, incluyo a las escritoras, se arrogan gran autoridad en el momento de escribir. Me parece que los autores argentinos, y las argentinas, son más compinches con el lector. Pero es una generalización, claro.

5. ¿Cuál es el/la autor/a chileno/a más argentino/a?

Obviamente habría que mencionar a Gonzalo León, Federico Galende, Alfonso Mallo, Cynthia Rimsky. Teatro vivo de lo trasandino como palabra especular. En un plano más "estético" o de programa, creo que Nicolás Poblete se acuesta hacia el lado argentino. Y en el plano de mi deseo, quisiera que Autobiografía de un ex - tremista perteneciera a un argentino llamado José Ángel Cuevas, pero que nació en la Sexta Región.

6. ¿Cuál fue el último libro que leyó de literatura chilena?

Un libro que destaco es Ensayo de eclipse, de Alfonso Iommi. Una sublime y sinuosa narración sobre un artista de la línea. Y por la docencia en la maestría de escritura, tengo la suerte de conocer muchos autoras y autores chilenos jóvenes. El último libro leído fue El calor, de Malu Furche, novela a publicarse en La Pollera. Temperatura elevada en varios sentidos.

7. ¿Cuáles son los tres autores chilenos que más ha leído?

Son cuatro: Diamela Eltit, Lina Meruane, Raúl Zurita y Cynthia Rimsky.

8. Sigmund Freud dice que para amar hacen falta tres, ¿qué otra literatura podría venir a completar esta escena?

Habría que elegir entre la uruguaya o la australiana.

9. ¿Cómo definiría la argentinidad en materia literaria?

¿Por qué hablar de lo argentino si venía hablando de Chile? Una de las cosas que más me intrigan de la narrativa chilena actual es la presencia omnipresente de los viajes en auto, la manera como el habitáculo en movimiento es plataforma múltiple de lo decisivo y provisional.

\section{Alejandra Costamagna}

Santiago, 1970. Ha publicado, entre otros, En voz baja (1996), Dile que no estoy (2007), Animales domésticos (2011), El sistema del taco (2018). 
1. ¿Qué libro ha releído de la literatura argentina? ¿Por qué motivo(s)?

Memorias de un pigmeo. Porque aquí el "método" Uhart se despliega solito, sin que asome ninguna costra. Este libro -que es un poco cuento, un poco novela, un poco ninguno de los anteriores- nos devuelve un asombro apacible, nos retira el manto de la inercia y nos encamina hacia un primer estado del cuestionamiento, de la extrañeza.

2. Si tuviera que elegir algún episodio para decir algo sobre las relaciones entre las literaturas argentina y chilena, ¿cuál elegiría y por qué?

El premio Iberoamericano de Narrativa Manuel Rojas, otorgado a Hebe Uhart en 2017. ¿Por qué? Asómense al inicio de su discurso de agradecimiento: "Yo no conocía la existencia de este premio Manuel Rojas, ni la del mismo Rojas, nunca lo había leído. Para esta ocasión leí Hijo de ladrón y a las veinte páginas pensé: «¿Cómo es posible que yo lo desconozca?» Es potente y directo, como a mí me gustan los escritores, es argentino de padres chilenos, se ve que ha pasado muchas veces la frontera".

3. ¿A qué autor/a de la literatura argentina envidia?

A César Aira por su capacidad de pelar cables.

4. ¿Qué característica(s) de la literatura argentina pondría de relieve en contraste con la literatura chilena?

Cierto desparpajo, cierto desborde, cierto caos, cierta horizontalidad, cierta frescura. No generalizaría, pero la narrativa de este lado de la cordillera tiende menos al extravío y al delirio. Cuesta más sacudir y abordar el ridículo de todos los días.

5. ¿Cuál es el/la autor/a argentino/a más chileno/a?

Manuel Rojas.

6. ¿Cuál fue el último libro que leyó de literatura argentina?

El corazón del daño, de María Negroni.

7. ¿Cuáles son los tres autores argentinos que más ha leído?

Hebe Uhart, Manuel Puig, Antonio Di Benedetto.

8. Sigmund Freud dice que para amar hacen falta tres, ¿qué otra literatura podría venir a completar esta escena?

La uruguaya. Aunque es tramposo, porque sería un amor doblemente fortalecido por el caudal de un río que es mucho más que un río. Sería un dos contra uno.

9. ¿Cómo definiría la chilenidad en materia literaria?

Paso.

\section{María Sonia Cristoff}

Trelew, 1965. Ha publicado, entre otros, Falsa calma (2005), Bajo influencia (2010), Inclúyanme afuera (2014), Mal de época (2017).

1. ¿Qué libro ha releído de la literatura chilena? ¿Por qué motivo(s)?

Poste restante, de Cynthia Rimsky; Sangre en el ojo, de Lina Meruane; El sistema del tacto, de Alejandra Costamagna: los doy siempre a leer en mis clases.

2. Si tuviera que elegir algún episodio para decir algo sobre las relaciones entre las literaturas argentina y chilena, ¿cuál elegiría y por qué?

Durante su estadía de casi una década en Buenos Aires, María Luisa Bombal entró en contacto con el grupo Sur. Se hizo especialmente amiga de Borges, con quien compartía también la fascinación por el cine. Atenta a ese gusto, Victoria Ocampo le pidió a Bombal que reseñara para la revista Sur la película Puerta cerrada, con Libertad Lamarque, porque consideraba que ningún argentino se rebajaría a hablar de una película local con una estrella tan cursi y porque, según palabras de la propia Bombal 
en su "Testimonio autobiográfico", dio por sentado que ella lo haría en el tono satírico que tan bien le salía en las conversaciones. Pero en cambio Bombal, sin dejar de reconocer que se trataba de "un melodramón", puso a la película y a su protagonista central por el cielo con sus elogios. De ese episodio me encanta el reconocimiento explícito a Libertad Lamarque, una de nuestras pocas artistas ácratas, y sobre todo me encanta ese gesto de Bombal de desmarcarse del entre-nos por momentos agobiante del grupo Sur. No es la primera vez que lxs escritorxs chilenxs de todas las épocas me generan una complicidad implícita, secreta, contra los centralismos literarios porteños: lo adscribo al hecho de haber nacido en la Patagonia, donde la proximidad con Chile es muy fuerte.

3. ¿A qué autor/a de la literatura chilena envidia?

A Juan Emar, profundamente.

4. ¿Cuál fue el último libro que leyó de literatura chilena?

Décimas: autobiografía en verso, de Violeta Parra.

5. ¿Cuáles son los tres autores chilenos que más ha leído?

Diamela Eltit. Cristián Huneeus. Joaquín Edwards Bello.

6. Sigmund Freud dice que para amar hacen falta tres, ¿qué otra literatura podría venir a completar esta escena?

La peruana, o la colombiana, o la boliviana. Cualquiera de las literaturas de América Latina, que en verdad son una, y que deberían serlo más.

7. ¿Cómo definiría la argentinidad en materia literaria?

Tomando con pinzas cualquier conversación que nos remita a las esencias, diría que subyace en la literatura argentina -al menos en cierta zona de la literatura argentina, la única que me interesa- aquella sugerencia borgeana de que quienes escribimos somos, ante todo, lectores.

\section{Diamela Eltit}

Santiago, 1949. Ha publicado, entre otros, Lumpérica (1983), El padre mío (1989), Mano de obra (2002), Sumar (2018).

1. ¿Qué libro ha releído de la literatura argentina? ¿Por qué motivo(s)

El inglés de los guesos porque la perra se llama Diamela

2. Si tuviera que elegir algún episodio para decir algo sobre las relaciones entre las literaturas argentina y chilena, ¿cuál elegiría y por qué?

El escritor chileno Manuel Rojas, nació en Argentina.

3. ¿A qué autor/a de la literatura argentina envidia?

Decidí, de manera estratégica y siguiendo a Melanie Klein, cambiar la envidia por la admiración, es ideal para dormir bien en las noches.

4. ¿Qué característica(s) de la literatura argentina pondría de relieve en contraste con la literatura chilena?

La Argentina cuenta con una sólida historia literaria, los autores chilenos se esfuerzan por destruirla.

5. ¿Cuál es el/la autor/a argentino/a más chileno/a?

Roberto Arlt.

6. ¿Cuál fue el último libro que leyó de literatura argentina?

Nuestra parte de la noche

7. ¿Cuáles son los tres autores argentinos que más ha leído?

Más de tres. 
8. Sigmund Freud dice que para amar hacen falta tres, ¿qué otra literatura podría venir a completar esta escena?

Bueno, Freud se quedó corto. Si se piensa en poliamor, no queda ninguna afuera.

9. ¿Cómo definiría la chilenidad en materia literaria?

Es un asunto de hombres, entre hombres.

\section{Yanko González}

Buin, 1971. Ha publicado, entre otros, Metales pesados (1998), Alto volta (2007), Objetivo general (2019), Los más ordenaditos. Fascismo y juventud en la dictadura de Pinochet (2020).

1. ¿Qué libro ha releído de la literatura argentina? ¿Por qué motivo(s)?

Relapso+Angola de Martín Gambarotta. Hay una apuesta por poetizar la política desde un lugar extraño, aunque no ajeno a nuestra tradición. No obstante, revitaliza desde el objetivismo -como Carl Rakosi- las oblicuas y absurdas relaciones entre poder y poesía.

2. ¿A qué autor/a de la literatura argentina envidia?

Envidio obras, no sé si autores. Poemas de Roberto Juarroz, de Juana Bignozzi, poemas encontrados de Esteban Peicovich, de Arnaldo Calveyra, de Verónica Viola Fisher, Fabián Casas, M. Gambarotta, de Marcelo Díaz, de W. Cucurto, Leonidas Lamborghini, de Mario Ortiz. Relatos de Fogwill, ensayos de Beatriz Sarlo... y muchos más.

3. ¿Qué característica(s) de la literatura argentina pondría de relieve en contraste con la literatura chilena?

Como no son sabuesos ni esclavos de los premios, ni esperan mendrugos literarios del Estado ni del empresariado -casi no los hay-, su literatura tiene vocación libertaria y derrocha radicalidad y movimiento.

4. ¿Cuál es el/la autor/a argentino/a más chileno/a?

Juan L. Ortiz, tiene la liricidad y la tristeza de este país flaco.

5. ¿Cuál fue el último libro que leyó de literatura argentina?

Releí Cinética de Edgardo Dobry y Rosario de Alejandro Rubio

6. ¿Cuáles son los tres autores argentinos que más ha leído?

Ignacio Anzóategui, personaje curiosísimo. Su Vida de muertos la he repasado varias veces junto a su marginalia. Los demás, supongo, se me cruzaron una y otra vez en mis tiempos formativos: Borges, Cortázar, Pizarnik...

7. ¿Cómo definiría la chilenidad en materia literaria?

Una literatura de la contención, a dos páginas de la autocensura.

\section{Betina Keizman}

Buenos Aires, 1966. Ha publicado, entre otros, Zaira y el profesor (1999), Los restos (2014), Recurso de amparo (2018).

1. ¿Qué libro ha releído de la literatura chilena? ¿Por qué motivo(s)?

Diez y Un año de Juan Emar. Inicialmente los leí por trabajo, volví por fascinación.

2. Si tuviera que elegir algún episodio para decir algo sobre las relaciones entre las literaturas argentina y chilena, ¿cuál elegiría y por qué?

Prefiero las anécdotas menores. Una charla de Alejandro Rubio en que un chico del público, probablemente otro poeta, le preguntó cómo había hecho su generación para insubordinarse con sus antecesores (había sido el tema principal de su charla, digamos) y él contestó: “¿Cómo? Simplemente nos cagamos en ellos”. Yo estaba ahí por error, pensando que el poeta invitado era el chileno Rafael Rubio. 


\section{3. ¿A qué autor/a de la literatura chilena envidia?}

Envidiar, a los poetas, siempre envidio a los poetas. Enrique Lihn, en primera línea.

4. ¿Qué característica(s) de la literatura chilena pondría de relieve en contraste con la literatura argentina?

A veces creo que los escritores chilenos están entre la espalda y la pared: por un lado, la mirada eficientista y lucrativa del neoliberalismo chileno que también domina el campo editorial, incluso en el caso de las editoriales llamadas independientes. Del otro lado, el peso sacrosanto del realismo y la "necesidad de expresar su tiempo", que el lector se identifique, pero de un modo algo elemental. Por supuesto que hay escritores chilenos que aportan aires frescos, son los que se atreven a experiencias y registros propios, entre otros, Geisse, Mellado, Rimsky. Si lo pienso mejor, me imagino que la literatura chilena es un conventillo (como todas las literaturas) con recovecos, muchas salas infravaloradas y numerosas sorpresas felices. En cualquier caso, tiene poco de construcción monumental (a menos que de poesía se trate). Pero esto no se debe a ninguna deficiencia en la calidad literaria, es la consecuencia de una academia debilitada y poco numerosa, y de la escasez de círculos de escritores o de lectores que propulsen recepciones alternativas. Geisse y otros están intentando rescatar a Alfonso Alcalde, por ejemplo, que bien lo merece. Es el tipo de operaciones que aportan diversidad y vigor a otras literaturas (me adelanto a la pregunta 8 y la comparo con las literaturas mexicana o argentina), relecturas, rescates, diversidad de voces, pero en la literatura chilena son insuficientes y están restringidas a los ámbitos universitarios, a ritmos de necesidades editoriales o a círculos casi herméticos, con sus propias agendas.

5. ¿Cuál es el/la autor/a chileno/a más argentino/a?

De los actuales, Mike Wilson.

6. ¿Cuál fue el último libro que leyó de literatura chilena?

Pobres diablos de Cristian Geisse, sin duda el más chileno entre los chilenos.

7. ¿Cuáles son los tres autores chilenos que más ha leído?

Manuel Rojas, Guadalupe Santa Cruz, Pedro Lemebel. Antes de llegar a Chile, había leído mucho a Bolaño, del que algunos se apropian bajo el calificativo de "latinoamericano". Una vez, un intelectual santiaguino me dijo que la prueba de que Bolaño es chileno era que odiaba Chile. Lo consideraba una prueba irrefutable de chilenidad. Disiento, pero la anécdota me parece reveladora.

8. Sigmund Freud dice que para amar hacen falta tres, ¿qué otra literatura podría venir a completar esta escena?

En mi caso, la mexicana. Son los tres extremos de mi cruz del sur, por circunstancias de la vida.

\section{9. ¿Cómo definiría la argentinidad en materia literaria?}

Alguien que contempla su ombligo, mete un dedo, rasca, extrae una pelusa, concluye que halló el aleph y que está en Buenos Aires. Lo mejor de la literatura argentina brilla cuando abandona esa argentinidad.

\section{Martín Kohan}

Buenos Aires, 1967. Ha publicado, entre otros, Dos veces junio (2002), Narrar a San Martín (2005), Fuera de lugar (2016), La vanguardia permanente (2021).

1. ¿Qué libro ha releído de la literatura chilena? ¿Por qué motivo(s)?

No aceptes caramelos de extraños de Andrea Jeftanovic, para escribir un texto de contratapa a su edición argentina. 
2. Si tuviera que elegir algún episodio para decir algo sobre las relaciones entre las literaturas argentina y chilena, ¿cuál elegiría y por qué?

El cruce de la cordillera con el que Sarmiento comienza Facundo. Chile (como Uruguay): afuera pero cerca. El exilio del que, yéndose, ya se dispone a volver.

\section{3. ¿A qué autor/a de la literatura chilena envidia?}

No envidio a escritores. Envidio a futbolistas. Por ejemplo: ¿qué se sentirá ganándole un clásico a Riber siendo el autor de los goles de la victoria? Pienso en Gary Medel, por supuesto.

4. ¿Qué característica(s) de la literatura chilena pondría de relieve en contraste con la literatura argentina?

No temo al lugar común: el predominio de los poetas.

5. ¿Cuál es el/la autor/a chileno/a más argentino/a?

Desisto de poner lo argentino como criterio. ¿Qué sería ser "más argentino"? No lo sé.

6. ¿Cuál fue el último libro que leyó de literatura chilena?

Chilean Electric de Nona Fernández o Lihn. Ensayos biográficos de Roberto Merino, uno de esos dos. Y antes, creo que Animales domésticos de Alejandra Costamagna. Todo indica que el próximo último será Poeta chileno de Alejandro Zambra.

7. ¿Cuáles son los tres autores chilenos que más ha leído?

Enrique Lihn, Roberto Bolaño, Parra, Neruda. Ya sé: dije cuatro. Dado que de todas formas me pasé, agrego: Diamela Eltit, José Donoso, Zurita. Y ya no pudiendo parar: Zambra y Lina Meruane.

8. Sigmund Freud dice que para amar hacen falta tres, ¿qué otra literatura podría venir a completar esta escena?

La de Uruguay.

9. ¿Cómo definiría la argentinidad en materia literaria?

El momento en el que el sargento Cruz se pasa a pelear junto a Martín Fierro, para irse después los dos a vivir entre los indios. Lo escribió José Hernández, lo reescribió Jorge Luis Borges.

\section{Lina Meruane}

Santiago, 1970. Ha publicado, entre otros, Los infantas (1998), Fruta podrida (2007), Sangre en el ojo (2012), Volverse Palestina (2013).

1. ¿Qué libro ha releído de la literatura argentina? ¿Por qué motivo(s)?

Silvina Ocampo, sus cuentos completos. Sylvia Molloy: Desarticulaciones. Jorge Barón Biza, El desierto y su semilla. Ernesto Sábato, Informe sobre ciegos. Jorge Luis Borges, su poesía y sus cuentos. Marta Dillón, Pablo Pérez y Daniel Link, sus escritos sobre la pandemia del sida. En todos los casos los releí porque los enseño o porque he escrito sobre esos libros y tanto incluirlos en mis cursos como escribir sobre ellos ha sido un placer.

2. Si tuviera que elegir algún episodio para decir algo sobre las relaciones entre las literaturas argentina y chilena, ¿cuál elegiría y por qué?

Los autores de ambos lados leyendo sus obras: en el caso argentino era una lectura sin énfasis, en el caso chileno era una lectura con intención performática; siempre he pensado que eso nos diferencia, los chilenos, al haber sido más marginales en la circulación literaria somos menos solemnes y nos jugamos más en la puesta en espacio, acaso para ser vistos y recordados...

3. ¿A qué autor/a de la literatura argentina envidia? 
La escritura de otros autores no me produce envidia sino admiración y alegría y en ese terreno puedo mencionar a Gabriela Cabezón Cámara y Ariana Harwicz, por la audacia de sus tramas y su atrevimiento en el lenguaje. En esa línea también pongo los relatos más desaforados de César Aira y de Iosi Havilio.

4. ¿Qué característica(s) de la literatura argentina pondría de relieve en contraste con la literatura chilena?

Encuentro en esa literatura más ánimo reflexivo: mucho en esa tradición son verdaderos relatos del pensamiento que funcionan como ensayos del yo. Aquí ubico por ejemplo a Sergio Chejfec, acaso el más connotado de ese modo de escritura tan poco frecuentada en Chile donde no encuentro que se ensaye el pensamiento en nuestra ficción.

5. ¿Cuál es el/la autor/a argentino/a más chileno/a?

Manuel Rojas.

6. ¿Cuál fue el último libro que leyó de literatura argentina?

Mariana Enríquez, Nuestra parte de noche y Samanta Schweblin, Kentukis

7. ¿Cuáles son los tres autores argentinos que más ha leído?

Alejandra Pizarnik, Julio Cortázar y Borges: creo haber leído sus obras completas.

8. Sigmund Freud dice que para amar hacen falta tres, ¿qué otra literatura podría venir a completar esta escena?

La uruguaya; me parece que hay sintonía entre estas tres literaturas.

9. ¿Cómo definiría la chilenidad en materia literaria?

Más que definirla, diría que veo como tendencia una escritura volcada al repaso de lo que fue la dictadura y sus efectos en el presente, e interesada en la reproducción (no necesariamente costumbrista) de una oralidad y modos del habla que nos particularizan.

\section{Cynthia Rimsky}

Santiago, 1962. Ha publicado, entre otros, Poste restante (2001), Los perplejos (2007), Ramal (2011), La revolución a dedo (2020).

1. ¿Qué libro ha releído de la literatura argentina? ¿Por qué motivo(s)

Ahora estoy releyendo La liebre y Ema, la cautiva de César Aira para pensar, buscar, desplegar la pregunta de qué pasa en Chile con la reescritura de la tradición.

2. Si tuviera que elegir algún episodio para decir algo sobre las relaciones entre las literaturas argentina y chilena, ¿cuál elegiría y por qué?

Serían dos migrancias. M. Luisa Bombal vino a Argentina en 1933, después del juicio que enfrentó por haber disparado a Sánchez. Aquí, en la cocina de la embajada de Chile, habitada por Pablo Neruda, escribió La última niebla, su primer libro, que fue publicado en Argentina con prólogo de Norah Lange. El segundo episodio es de Marta Brunet. Durante su estadía como diplomática en Argentina hizo una torsión a su escritura, saliéndose definitivamente del realismo, lo que a su regreso a Chile no será bien visto por la crítica.

3. ¿A qué autor/a de la literatura argentina envidia?

Más que a un autor o una autora en especial, lo que envidio de los y las autoras argentinas es la idea y la práctica "de que la literatura es pura invención y no la transposición literaria del material mítico-social disponible, es decir de los sentidos sobre los que vive una sociedad en un momento histórico dado" (Aira). 
4. ¿Qué característica(s) de la literatura argentina pondría de relieve en contraste con la literatura chilena?

Pondría en relieve la forma en la que leen las tradiciones de su literatura, su conversación permanente con ellas en los libros que escriben, el trabajo de relectura irónico, descarado, desfachatado, delirante incluso, la naturalidad con la que las incorporan y las desafían.

5. ¿Cuál es el/la autor/a argentino/a más chileno/a?

Supongo que Manuel Rojas.

6. ¿Cuál fue el último libro que leyó de literatura argentina?

Un libro de cuentos para niños de Valeria Tentoni, Viaje al fondo del río.

7. ¿Cuáles son los tres autores argentinos que más ha leído?

María Moreno, M. Sonia Cristoff, Pablo Katchadjian.

8. Sigmund Freud dice que para amar hacen falta tres, ¿qué otra literatura podría venir a completar esta escena?

Argentina es la tierra, lo plano. Chile, la cordillera, el accidente. Le agregaría una literatura de mar, insular, como Cuba.

9. ¿Cómo definiría la chilenidad en materia literaria?

El escudo dice: Por la razón o la fuerza. En materia literaria sería lo razonable. Como eso es tan fuerte, cuando se logra romper, surgen escrituras muy potentes y explosivas

\section{Hernán Ronsino}

Chivilcoy, 1975. Ha publicado, entre otros, Glaxo (2009), Lumbre (2013), Notas de campo (2017), Cameron (2018).

1. ¿Qué libro ha releído de la literatura chilena? ¿Por qué motivo(s)?

Los poemas de Zurita y Elvira Hernández. Me gusta, cada tanto, leer una ráfaga de esa intensidad que los atraviesa. También releí a Pezoa Véliz, La partida fantasma de Sanhueza, los cuentos de Costamagna, Sangre en el ojo de Meruane.

2. Si tuviera que elegir algún episodio para decir algo sobre las relaciones entre las literaturas argentina y chilena, ¿cuál elegiría y por qué?

La literatura argentina desde hace unas décadas vive contemplando su propio ombligo, sin tener un panorama claro de lo que está sucediendo, por ejemplo, en América latina. Y en América latina están pasando muchas cosas muy potentes. Chile es parte de esa potencia que muestra la literatura contemporánea. Y los canales de comunicación y de circulación de libros, sin duda, son mucho más estrechos con el resto de América latina que lo que sucede en Argentina.

3. ¿A qué autor/a de la literatura chilena envidia?

Admiro a muchas y muchos.

4. ¿Qué característica(s) de la literatura chilena pondría de relieve en contraste con la literatura argentina?

Creo que la "intimidad" puede ser un tema que atraviesa de diversas formas lo familiar, lo político, lo popular, lo poético. Es decir, lo íntimo en todas sus variantes.

5. ¿Cuál es el/la autor/a chileno/a más argentino/a?

Bolaño o Manuel Rojas.

6. ¿Cuál fue el último libro que leyó de literatura chilena?

La revolución a dedo de Cynthia Rimsky.

7. ¿Cuáles son los tres autores chilenos que más ha leído?

Bolaño. Celedón. Gómez Morel. 
8. Sigmund Freud dice que para amar hacen falta tres, ¿qué otra literatura podría venir a completar esta escena?

La literatura uruguaya.

9. ¿Cómo definiría la argentinidad en materia literaria?

Hace más de cincuenta años Gombrowicz dijo sobre este asunto que la literatura argentina no deja de pensarse a sí misma, trata de entender qué significa ser argentinos, en la pregunta sobre el "nosotros" está el problema, dice Gombrowicz. Creo que algo de eso perdura. 